\title{
EXCEÇÃO, GOVERNAMENTALIDADE E POLÍTICAS DE SEGURANÇA
}

\author{
EXCEPTION, GOVERNMENTALITY AND SECURITY POLICIES
}

Fernanda Martins

Augusto Jobim do Amaral

\section{Resumo}

A vigilância e os controles transnacionais burocráticos trabalham atualmente a distância para rastrear e controlar até mesmo os movimentos de populações. Para refletir sobre tais políticas de segurança no espaço transnacional, torna-se fundamental o argumento de Bigo que antevê, no atual contexto, aquilo que ele chama de "banóptico". Combinando a ideia de "exclusão" (bando) de Jean-Luc Nancy com o "óptico" de Foucault, ele indica como as técnicas de elaboração de perfis são utilizadas para saber quem deve ser objeto de vigilância estrita. 0 diagrama estratégico consiste em determinar uma minoria como excluída, desde discursos de riscos a inimigos internos, passando pelas instituições, como os centros de detenção até as portas de embarque dos aeroportos, cruzando-se com leis e medidas administrativas que singularizam o tratamento de certo grupo.

Palavras-chave: Exceção. Segurança. Governamentalidade. Banóptico. Transnacionalidade.

\begin{abstract}
In order to think about security policies in the transnational space it is essential Bigo's argument that predicts, in the present context, something he calls "ban-opticon". Combining the idea of "exclusion" from Jean-Luc Nancy with "optical" from Foucault, the author shows how the of profiling techniques are used to find out who should be the target of strict monitoring. Surveillance and transnational bureaucratic controls work with distance to trace and control even population shifts. The strategic diagram creates an excluded minor-
\end{abstract}


ity, from on discourses of risk to internal enemies, using to institutions such, as detention centers and boarding gates, intersecting with laws and administrative measures to individualize the treatment of a certain group.

Keywords: Exception. Security. Governmentality. Banóptico. Transnacionality.

\section{INTRODUÇÃO}

Para entender em que panorama se instalaram as novas tecnologias de controle, se diria melhor, securitárias - e de que forma o fazem - sua lógica, características, (re)configurações, reflexos -, melhor é compreender pouco mais uma "história das tecnologias". Foucault já havia alertado, dentro de seus estudos sobre biopolítica e "governamentalidade", precisamente sobre os diferentes mecanismos contemporâneos implementados tendo como mote a segurança.

O que poderíamos entender, antes, por segurança? Propriamente sobre os dispositivos que se implementam e, de alguma forma, vão sustentar uma biopolítica ${ }^{1}$ - governamentalidade ${ }^{2}$ sobre a população? Diante de três momentos exemplares, a tarefa ficaria facilitada, segundo Foucault (2006c, 16-21). Se, desde um primeiro caso, podemos ter uma lei sob a forma de proibição e seu correlato castigo, numa segunda modulação a esta lei pode-se agregar uma série de vigilância e correções a quem a infringe. Todavia, num momento último, a partir da mesma matriz - aquela mesma lei penal, enquadrada de uma parte pela vigilância e, por outra, pela correção -, desta vez a aplicação da lei, sua organização preventiva e de correção poderão estar estritamente governadas por uma série de questões gerenciais de outro tipo, como se percebe no argumento de Bigo que antevê no atual contexto aquilo que ele chama de "banóptico". Combinando a ideia de "exclusão" (bando) de Jean-Luc Nancy com o "óptico" de Foucault, indica como as técnicas de elaboração de perfis são utilizadas para saber quem deve ser objeto de vigilância estrita nas políticas de segurança no espaço transnacional.

A primeira forma descrita consiste no mecanismo legal/jurídico sistema legal arcaico reinante na Idade Média até os séculos XVII-XVIII -, uma partição binária entre o permitido e o vedado, do acoplamento 
entre uma ação proibida e um tipo de castigo. 0 segundo mecanismo (que poderíamos chamar moderno, introduzido a partir do século XVIII), tão caro ao momento posto em Vigiar e Punir, é caracterizado - dentro do sistema binário, pela vigilância e correção - por fazer aparecer o personagem do condenado. Sobre ele recai o ato judicial de castigo, ademais combinado com uma série de técnicas policiais, médicas, psicológicas, que correspondem à transformação do indivíduo. Aí o mecanismo disciplinar (FOUCAULT, 1987, p. 117 ss.). A terceira forma, sim, corresponde já aos dispositivos securitários. Uma outra distribuição de uma série de fenômenos, como novas formas de penalidade, pela inserção do cálculo de custos, dos limites do aceitável etc., coloca uma terceira variável contemporânea em jogo, organizadora de uma biopolítica (entendida como o conjunto de mecanismos por meio dos quais aquilo que constitui os traços biológicos da espécie humana, a partir do século XVIII, passa a fazer parte de uma estratégia política ( FOUCAULT, 2006c, p. 15).

\section{SEGURANÇA E HISTÓRIA DAS TECNOLOGIAS}

Na avaliação contemporânea de como pensar a penalidade e verificar como ela se exerce, o problema deve-se colocar em termos de segurança. A relação econômica é que se torna fundamental dentro de uma análise de custo da repressão e da delinquência, o que tem provocado, como se disse, a multiplicação de mecanismos disciplinares, mas não somente eles, também uma espécie de reativação e transformação destas técnicas, juntamente com as anteriores técnicas jurídico-legais. Uma nova economia geral de poder convida a passar pela segurança mais estritamente, quer dizer, a um modo de exercer o poder não mais vinculado, nem meramente à partição binária da exclusão, correlata à época dos leprosos na Idade Média, nem relativo aos regulamentos de tipo disciplinar, como a quarentena dos períodos da peste (FOUCAULT, 2001, p.54-65; FOUCAULT, 1987, p. 162-165). Está-se diante de problemas como os das epidemias (as de varíola, destaca Foucault, a partir do século XVIII), do contágio e das campanhas médicas: a segurança é, antes, "uma maneira de somar, de fazer funcionar, além dos mecanismos de segurança propriamente ditos, as velhas estruturas da lei e da disciplina " (FOUCAULT, 2006c, p. 
26). Se, de uma forma pouco mais superficial e esquemática, pudéssemos atrelar a soberania aos limites de um território, a disciplina sendo exercida sobre o corpo dos indivíduos, por fim, como sede da segurança, teríamos o conjunto de uma população. Obviamente, isto é dizer pouco, pois o que todos comungam, desde diferentes funcionamentos, é de um problema de gestão das multiplicidades - a seu modo - como ver-se frente ao múltiplo (FOUCAULT, 2006c, p. 27-8).

Como rasgos essenciais dos dispositivos de segurança, o que nos interessa, em sede preliminar, tem a ver com o seu espaço. A segurança, como técnica política, acondiciona um meio (entendido como suporte e elemento de circulação de uma ação) em função de uma série de acontecimentos possíveis, ou seja, regula a aleatoriedade inscrita num espaço dado. Daí é que vêm situar-se no século XVIII as cidades como problema central, não mais como na época dos espaços murados e estreitos da soberania, mas como espaços de circulação da heterogeneidade social e econômica (FOUCAULT, 2006c, p. 40-44). Segundo aspecto: da maneira de tratar o aleatório e do problema da naturalidade da espécie num meio artificial surge, exatamente, o substrato do que se poderá chamar de biopolítica ou biopoder. É uma nova racionalidade governamental que aparece atrelada agora ao que se chama de população. Desaparece a escassez como flagelo, vira uma quimera tratável apenas ao nível da produção, não ao nível propriamente da multiplicidade de indivíduos que vão morrer. A permissividade de deixar que as coisas caminhem, aberta pelo liberalismo, põe como objetivo final a noção de população.

A maneira de se tratar o acontecimento é completamente outra no que tange à segurança. Resumidamente, diz Foucault (2006c, p. 66-71) que a disciplina é centrípeta, funciona isolando o espaço, concentrando, circunscrevendo um local no qual seu poder possa atuar plenamente. Já os dispositivos securitários têm uma tendência muito importante para ser notada atualmente em nosso contexto contemporâneo: são expansivos - caracteriza-se a segurança por ser centrífuga.

Integra sem cessar novos componentes, desenvolvendo circuitos cada vez maiores. Por outro lado, na medida em que a disciplina regula tudo, nada deixando a descoberto, nem mesmo a menor ação, a segurança tem a permissibilidade que notamos como traço indispensável: "deixar 
fazer", mote do liberalismo. Ao fim e ao cabo, ainda, como característica diferenciadora desta nova dinâmica, mais importante é antever nos códigos legais, nas suas determinações de proibições, um conjunto negativo de pensamentos e técnicas ("imagina o negativo"), ao passo que nos mecanismos disciplinares, ainda que se mantenha uma codificação binária (obrigatório e proibido), a ênfase está muito menos naquilo que não se deve fazer do que exatamente naquilo que se deve fazer (trabalha no "complemento da realidade"). No sistema legal, o indeterminado é que está permitido, no sistema de regulamento disciplinar, o determinado é o que se deve fazer, o resto indeterminado é proibido. Os dispositivos securitários, ao contrário, vão funcionar a partir de uma realidade que não trata de adotar o ponto de vista nem daquilo que se impede nem daquilo que é obrigatório, salta-se a uma distância suficientemente capaz de captar donde as coisas, desejáveis ou não, vão produzir-se: "em outras palavras, a lei proíbe, a disciplina prescreve e a segurança [...] tem a função essencial de responder a uma realidade de tal maneira que a resposta a anule: a anule, a limite, a freie e a regule. Esta regulação no elemento da realidade é, creio, o fundamental nos dispositivos de segurança." (FOUCAULT, 2006c, p. 69). À diferença de trabalhar no imaginário como a lei, de trabalhar, como a disciplina, no "complemento" da realidade (prescrições e obrigações artificiais), a segurança preocupa-se em atuar na realidade mesma. Por isso, o liberalismo e sua ideia de liberdade são a sua vez ideologia e técnica política de governo conexas a este cenário. 0 jogo de deixar que as coisas passem e transcorram é, fundamentalmente, fazer com que a realidade (entenda-se o mercado como local de veridição) desenvolva-se e caminhe. Assim, pois, o problema da liberdade toma assento principal. Liberdade minuciosamente ditada - não aquela de oposição ao poder, contra os abusos do governo, mas aquela convertida em elemento indispensável para o governo - e correlata aos dispositivos de segurança. Em linhas gerais, vale afirmar, a liberdade de comportamento no regime liberal, nesta arte liberal de governar a liberdade não é um dado pronto a ser respeitado, mas uma região a ser produzida, regulamentada e organizada: "o liberalismo não é o que aceita a liberdade. 0 liberalismo é o que se propõe fabricá-la a cada instante [...]”. (FOUCAULT, 2008, p. 88). Para tanto, convoca como princípio de cálculo o que se chama segurança. 
Deve-se gerir constantemente até que ponto os diferentes interesses não constituirão um perigo para o dos demais.

O jogo permanente entre liberdade e segurança é que está no âmago dessa nova razão governamental, da economia de poder própria do liberalismo. Arbitrar a liberdade e a segurança em torno da noção de perigo, ter o governo como gestor dos perigos nada mais representa que uma das implicações fundamentais do liberalismo: o estímulo ao "viver perigosamente". 0 medo do perigo, portanto, acaba sendo, segundo Foucault (2008, p. 91), o correlato psicológico e cultural interno do liberalismo. Desdobramento este que se poderia apontar para além desta cultura do perigo catapultada pelo liberalismo, como anverso da extensão formidável dos dispositivos de controle, para além da forma do governo liberal tout court da qual o pan-óptico seria o melhor retrato. Tais dispositivos somente podem funcionar bem sob a condição de uma tal liberdade, preocupada na gestão do movimento, da circulação.

Insistindo pouco mais na diferenciação entre segurança e disciplina, há que se ver o descompasso entre a dita normalização disciplinar e a securitária. Aquela analisa os lugares, os gestos, os tempos, as operações e decompõe os indivíduos para, mais que percebê-los, modificá-los. A grelha disciplinar classifica os elementos em função de objetivos determinados, estabelece sequências e coordenações otimizadas, fixa procedimentos de adestramento e controles permanentes (FOUCAULT, 1987, p. 177 ss.). A partir daí, faz uma partilha entre o normal e o anormal, desde um modelo ótimo. 0 normal, obviamente, é aquilo capaz de se adequar à norma postulada; ela, sim, é o fundamental, não a dicotomia em si, por isso seu caráter prescritivo a que aludimos: "o que ocorre nas técnicas disciplinares trata-se mais de uma normação do que uma normalização" (FOUCAULT, 2006c, p. 76), devido efetivamente ao caráter fundamental e primário da norma. Porém, o nó crucial nos dispositivos de segurança, como indicamos, é o risco, melhor dizendo, o cálculo dos riscos, que, por suposto, é diferenciado de acordo com uma maior zona de risco que, por consequência, poderá identificar zonas mais ou menos perigosas. Assim, perigo e risco são trazidos ao centro da questão. Estatísticas, assim, poderão instrumentalizar índices, por exemplo, aceitáveis de mortalidade no caso referido da epidemia de varíola no século XVIII - e vamos longe 
até hoje com a inundação nos assuntos de segurança pública com a chamada criminologia atuarial, "empírico-abstrata" pronta a dar respaldo ao discurso oficial do controle do delito e de baixíssima intensidade imaginativa (cf. YOUNG, 2011, p. 10-23 e FERRELL, 2012, p. 157-176). Ao inverso do sistema disciplinar, em que se parte de uma norma e deduz-se a distinção entre normal e anormal, assinalam-se nos dispositivos de segurança diferentes curvas de normalidade, passam a interagir distintas atribuições de normalidade. Opostamente, a primazia está no normal, melhor, no jogo das normalidades diferenciais, e a norma será deduzida apenas depois disto. Por esta razão, aqui sim, mais adequado dizer que se trata propriamente de normalização (FOUCAULT, 2006c, p. 74-76).

Relativamente a um terceiro aspecto, no tocante à referida população, tanto a escassez quanto a epidemia possuem um laço comum: como dissemos, o fenômeno da cidade. Ela se converte em problema central entre os séculos XVII e o início do XIX, e novos mecanismos de poder foram necessários para dar alguma resposta. Desde aí, o exercício de soberania não poderá deixar de passar por outra coisa senão pela circulação nas cidades. Já não mais a segurança do príncipe ou do território, mas a da população. Mais interessa fazer atuar os elementos de realidade do que uma obediência total a um soberano. Estes mecanismos de segurança, agora, não tendem a impor uma vontade de forma homogênea e contínua, tal como no sonho mais velho e antigo dos soberanos, que era o ideal do pan-óptico. A ação governamental passa a ser pautada, no século XVIII, pela necessidade e suficiência, ou seja, por um conjunto de mecanismos que incorpora fenômenos muito específicos que fazem atuar aquilo que chamamos população. Personagem político novo, dotado de uma natureza tal, não uma coleção de sujeitos jurídicos em relação de subordinação a uma vontade soberana, mas como um conjunto de elementos que se inscreve num regime geral de seres vivos ("espécie humana)" e serve de referência aos procedimentos de governo. Operador que acabou por inclinar um conjunto largo de saberes e, nem por isso, muito pelo contrário, deixa de ser superfície de aderência perfeita às transformações autoritárias. No momento em que o gênero humano aparece como espécie nasce o público. É ele o campo suscetível, como superfície de agarre, a sofrer a atuação do governo, e de um novo domínio de saber que é a economia política. Sob a 
sequência de mecanismos de segurança-população-governo emerge uma nova arte de governar assentada na ciência política, dominada por um regime de técnicas de governo em torno da população e, por conseguinte, em torno da chamada economia política (FOUCAULT, 2006c, p. 77-108).

Mas nada disto fez diluir o problema da soberania nem da disciplina. Radicalmente o oposto. Uma sociedade de governo, poderá dizer-se, apenas plantou noutros termos mais agudos ainda aqueles antigos desafios. Por isso, o epicentro de uma história que aqui se coloca tem na palavra "governamentalidade" seu ponto principal. Entendida, suma, como conjunto de instituições, procedimentos, análises, reflexões, cálculos, táticas que permite exercer uma forma complexa de poder sobre a população, por uma forma de saber que é a economia política e por instrumentos técnicos essenciais que são os dispositivos de segurança. Isto não elide entender a expressão como a proeminência de um tipo de poder que podemos chamar governo. Ademais, pode ser vista como resultado de um processo através do qual o Estado de Justiça da Idade Média (uma "sociedade da lei") foi convertido em Estado Administrativo (nascido de uma territorialidade correspondente a uma "sociedade de regramentos e disciplina") durante os séculos XV e XVI e, finalmente, se "governamentalizou" pouco a pouco, ou seja, passou a ser definido não mais por um território, mas por uma superfície ocupada por uma massa: a população, instrumentalizada por um saber econômico e controlada por dispositivos de segurança (FOUCAULT, 2006c, p. 134-137).

Como já se assinalou, ao menos desde os anos setenta do século $\mathrm{XX}$, pode-se notar uma certa modificação no rearranjo proeminente das técnicas de segurança, em detrimento dos aspectos disciplinares, não por outro motivo senão por uma visão do crime agora interpretado como comportamento econômico. Com isto, pouco haveria sentido em requisitar plenamente mecanismos de normalização geral e de exclusão, senão limpar o terreno, como disse Foucault (2008, p. 354-5), a processos oscilatórios “tolerantes", em que a intervenção não seria de sujeição interna, mas propriamente de tipo ambiental.

Tendo diante de si este quadro pormenorizado é que Deleuze aconselhou, ao longo dos seus trabalhos, aprofundar a retomada no estudo das práticas de poder. Talvez se tenha depositado sobre isto pouca 
atenção, principalmente nos meios jurídicos oficiais. Especialmente em entrevista televisiva célebre e, sobretudo, naturalmente em sua análise foucaultiana (DELEUZE, 2006, p. 78-100), Deleuze retomava a terminologia de análise das três práticas do poder: o Soberano, o Disciplinar e, sobretudo, o de Controle. ${ }^{3}$

Não que a sociedade disciplinar tenha acabado - dito antes à exaustão -, mas que já não somos exatamente isto, e a própria entrada em cena de novos mecanismos de sanção, educação e tratamento não nos deixa enganar. 0 alvorecer desta nova configuração de sociedade não é novidade; alertava-nos, antes mesmo de Foucault, nos anos 40, Burroughs. ${ }^{4}$

Vivenciadas já as sociedades de soberania - ao menos até o século XVIII, com a transição operada por Napoleão -, em que interessava mais decidir sobre a morte do que gerir a vida (FOUCAULT, s/d., p. 125 ss.), certamente também não estamos mais apenas fixados nos meios de confinamentos tradicionais de uma sociedade disciplinar. Sociedades estas características dos séculos XVIII e XIX, com o apogeu no início do século $\mathrm{XX}$, dotadas exatamente da passagem do indivíduo por moldes como a família, a escola, a caserna, a fábrica, de vez em quando o hospital e, notadamente hoje em dia, não eventualmente, a prisão - instituições totais, como apregoou Goffman (1999, p. 13-118) - estas formas sociais são dispostas a concentrar e distribuir o espaço, ordenar o tempo, maximizando a força produtiva de sujeitos disciplinados.

Como visto, à crise destas formas não cansa de se dar alarde. 0 que não se acode normalmente é, afinal, o fato de que apenas um olhar próximo da ingenuidade não perceberia que são exatamente elas, como eixos modelares de um tipo social, as primeiras a se dar conta da sua situação crítica. Noutros termos, diga-se melhor, é a perversa inflexão do "centro", captada por Martins (2007, p.150-151), pois conscientes de sua própria crise de centralidade, tais espaços fechados se dirigem agora a zonas potenciais de ensaio. É a própria crítica aposta que faz despertar nestes locais o pressentimento de sua ruína, acarretando, em algum nível, antecipações, metamorfoses, a sua perda de domínio. Não por outro motivo, vivemos em certa medida uma era de crise, retratada na sempre premente necessidade de "reforma das instituições": reforma dos hospitais, da educação, da indústria, da prisão etc. 
Portanto, ao que parece, a lógica foi transformada (não superada) em alto grau. As sociedades disciplinares têm dois polos amplamente explorados e de fácil identificação: o binômio indivíduo/massa. 0 poder aqui é massificante e simultaneamente individualizante, ou seja, molda a individualidade de cada membro do corpo, assim como assinala sua posição numa massa - é o poder do pastor ou tecnologia pastoral, segundo Foucault, regulado por palavras de ordem sobre o rebanho e sobre cada um dos animais - ter os olhos postos em todos e em cada um (omnes et singulatim) (FOUCAULT, 2006b, p. 15 ss.). Segundo Deleuze, adiante, nas sociedades de controle, o essencial não será mais a assinatura que identifica o indivíduo ou o número de matrícula que o posiciona numa massa, mas o que o regulará será uma linguagem numérica. Falamos aqui de uma cifra, mais propriamente de senhas que marcam nosso cotidiano pelo acesso ou rejeição à informação. Em considerável medida, apenas acessamos e, sobretudo, somos acessá(í)veis desta maneira. Cartões eletrônicos de todas as espécies: de crédito, para ligar o automóvel, para entrar em casa, no trabalho, apenas para ficarmos em exemplos fugazes. Acessamos bancos de dados e, sobretudo, fazemos parte de milhões deles, dos mais diversos multiplicados ao infinito, que demandam suas devidas senhas ou registro, óptico ou digital - demonstrando como os indivíduos podem se tornar "divisíveis" como meras amostras de mercado - capazes de antecipar quiçá nossos próprios desejos. Por isso, nesta nova pele da cultura informática, vemo-nos falando em "trocas flutuantes", necessariamente "surfando" freneticamente na rede, "em órbita" nesta diferente maneira de viver as relações com outrem. ${ }^{5}$

Arremata Deleuze (1992, p. 222), para dar as tintas desse novo contorno que se deve aprender a lidar: a velha toupeira monetária é o animal dos meios de confinamento, mas a serpente o é das sociedades de controle. Certamente, o poder que comporá estes dispositivos - Foucault disse que ele se exerce a partir de inúmeros pontos e vem de baixo -, se considerado abstratamente, orienta-se apenas em sua rede de galerias, em sua toca múltipla, por isso não vê e não fala: como se fosse uma toupeira (DELEUZE, 1992, p. 89). Metaforicamente, diferente da serpente, sinuosa em seus movimentos, sagaz e surpreendente no bote, que se esgueira maliciosamente nos recônditos do controle absoluto. 
Por outro lado, as máquinas a que cada tipo de sociedade faz corresponder são outras. Aquelas que exprimiam formas peculiares simples das antigas sociedades de soberania poderiam ser vistas nos relógios, nas alavancas e roldanas; passadas depois, nas sociedades disciplinares recentes, para as máquinas energéticas, em que o perigo se depositava na sabotagem. Atualmente, operam máquinas de terceira espécie, máquinas informáticas, em que o perigo ativo está na pirataria e na introdução de um vírus. Mas elas em si pouco nos dizem, senão quando perquirimos sobre os agenciamentos coletivos de que fazem parte (DELEUZE, 1992, p. 216).

Como ressaltado, encontramo-nos naquilo que se poderia chamar de crise generalizada de todos os meios de confinamento, alguns chamarão de "crise das instituições". Indaga-se: sendo assim a lógica que se anuncia, não devemos parar para analisar as formas ultrarrápidas de controle ao ar livre que substituem ou se agregam às antigas disciplinas? Como não conectar isto à constante metamorfose que vem se operando no próprio capitalismo? De que maneira abrir mão da análise de um sistema imanente que não para de expandir seus próprios limites, que se (re)encontra ampliado e entregue ao seu limite, que é o próprio Capital? Será tão árduo assim perceber que os arcaicos confinamentos como a prisão, verdadeiros moldes, estão ficando démodé? Não será porque os emergentes controles são muito mais condizentes com este ambiente, já que são modulações em si, quer dizer, moldagens maleáveis, reconfiguráveis continuamente?

Por certo, sobretudo, trata-se, a rigor, de uma radical mudança da dinâmica do capitalismo. Não mais existe radicalmente aquele modelo de capitalismo do século XIX, centrado na fábrica, fundado na concentração de capital e voltado para a produção, quando o mercado era conquistado pela colonização, pela redução dos custos ou ainda pela especialização. Se aquele capitalismo era dirigido para a produção, a atual performance do capital é voltada para a sobreprodução. 0 que se vende, como diz Deleuze (1992, p. 224), são serviços e o que se compra são ações. Compram-se produtos acabados ou montam-se peças destacadas. 0 produto impera, não a produção, agora relegada a algum país de terceiro mundo. Os mercados são conquistados, assim, por fixação de cotações e transformações do produto. Por isso, não mais a fábrica concentrada, mas a dispersa empresa. Os antigos confinamentos são agora figuras cifradas 
deformáveis de uma mesma empresa que só necessita de meros gestores. Em substituição, emerge a máfia S.A., na linguagem de Warat (2010, p. 14), um gigantesco agenciamento anônimo - para não dizer mafioso - em escala planetária. Enfim, os antigos espaços analógicos que convergiam para algum proprietário, público ou privado, parecem ser agora figuras de uma mesma entidade que dispensa um corpo e necessita de simples gestores (ŽIŽEK, 2016, p. 16).

Sintetizará Deleuze (1992, p. 224), do homem confinado para uma espécie de homem endividado. É óbvio - diversos horizontes já se afiguram para confirmar esta expectativa - que neste processo agônico dos meios disciplinares - não se diga que eles tenham se findado - as novas forças que se instalam deverão enfrentar a explosão dos guetos e favelas - Wacquant (2001, p. 7-12) confirma o alerta, quer dizer, controlar aqueles que, de certa forma, são pobres demais para alguma dívida ou numerosos demais para o confinamento.

\section{GOVERNO \& SEGURANÇA - ATRAVÉS DA EXCEÇÃO}

Virilio (1993), por sua vez, acertadamente, não para de investir na análise destas formas ultrarrápidas de controle ao ar livre inclusas nestes meios securitários. Numa cidade superexposta, com indivíduos sobre-excitados, ilustrativamente, dirá o autor que são em ambientes como os aeroportos, locais de uma regulação essencial das trocas e das comunicações, que verificamos zonas de forte experimentação de controle e vigilância máximos (VIRILIO, 1993). É através desses espaços que se verifica como manobras de grandes corporações aliadas a estratégias políticas convergem para o fortalecimento da informática e da biométrica como mecanismos de vigilância que incidem sobre movimentos transfronteiriços de indivíduos determinados (BIGO, 2006, p. 34).

Assim, como fica ali evidenciado, não se trata mais, como no passado, de isolar o suspeito pelo encarceramento, já que se trata, sobretudo, de interceptá-lo em seu trajeto. Assim desta forma se aparelham, como afirma Virilio (1993), até mesmo os setores de segurança máxima das mais modernas prisões. São eles equipados com pórticos magnéticos, 
equipamentos de maior liberdade de deslocamento, que servirão, paradoxalmente, como modelo do encarceramento penitenciário.

Os atuais e redistribuídos poderes de controle são novos arranjos melhorados, que as técnicas de outrora jamais imaginaram sonhar. Os atuais bancos de dados paradoxalmente denunciam bem a nova lógica: você só poderá garantir sua entrada em algum deles - e atualmente grande parte das conexões sociais são por eles regidas - se suas credenciais forem oferecidas e suas informações disponibilizadas para que ali, estando plenamente contido, consequentemente possa idealmente se movimentar.

No sentido da gestão do movimento e das novas tecnologias de controle, parece necessário, para refletir particularmente sobre as políticas de segurança no espaço transnacional, pensar em como a regra do estado de emergência fundamentada em discursos policiais, militares, alfandegários e judiciais (BIG0, 2006, p. 43) se faz alicerçada nas narrativas de defesa da livre circulação de sujeitos e mercadorias em espaços transnacionais de maneira vinculada ao controle contínuo e a distância desde a ideia de exceção.

O controle de circulação de imigrantes, minorias e daqueles que buscam asilo operacionaliza um novo campo de controle estabelecido na criação de imagens de novos inimigos, campo este que transborda para além de fronteiras. Os subterfúgios do terrorismo, do crime organizado, do tráfico de drogas ou inúmeras outras construções narrativas de controle emergencial permitem que regras de exceção materializem suas tendências de se tornarem permanentes através do exercício da exclusão definitiva de determinados grupos de sujeitos. Em nome da segurança e diante da hipótese de futuros comportamentos "perigosos", o banóptico como normalização securitária - argumento de Bigo fundamentado na "exclusão" (bando) de Jean-Luc Nancy (1983) com o "óptico" de Foucault - indica como as técnicas de elaboração de perfis e a transnacionalização das burocracias de vigilâncias configuram novas formas de dominação através de redes heterogêneas e transversais de controle que se propõem a vigiar e controlar os movimentos de forma ampla, mas que ocultam em sua oposição o policiamento de um número reduzido de pessoas (BIGO, 2006, p. 6). 
Ainda, reconhecer a história das tecnologias exige considerar também que a própria noção clássica de Estado e de soberania está flexibilizada pela transnacionalização de burocracias das agências de controle que se estabelecem em três critérios: no desenvolvimento de práticas de exceção, na elaboração de perfis e controle de estrangeiros e na normatização da mobilidade (BIG0, 2006, p. 6). Operacionalizadas através do regime de verdade de insegurança as mudanças implicadas aos agentes de vigilância dos Estados atravessam as bordas do espaço soberano estatal, relacionando-se, portanto, cada vez mais com atividades que assegurem o controle transfronteiriço. 0 que significa dizer que através da produção desse regime de verdade e através da declaração de combate às atividades que "legitimam" o medo e a insegurança nacional, verifica-se que os profissionais da (in)segurança criam estratégias para extrapolar os limites territoriais. É através das agências de inteligências e dos procedimentos de controle de circulação de sujeitos e mercadorias que as burocracias desenvolvem suas fontes de conhecimento e de poder simbólico na transnacionalização de suas operações. É o delineamento de território apagado pelo estado de emergência que visa controlar populações (BIGO, 2006, p. 6).

Suma, quanto mais dados forem fornecidos mais livremente você poderá se movimentar. Tão "livremente" controlado a ponto de se conseguir, como sabemos, pela interconexão de bases de dados, antecipar os gostos e desejos de qualquer um. Talvez os bancos de dados, agora com fins criminais, apenas escancarem e denunciem o real que esta sedução à vigilância pode acarretar. Aparentemente sem coerção, globalmente, somos expostos à vigilância e ao controle em um grau jamais visto (PASSETTI, 2007, p. 28-34).

Apesar de os novos instrumentos de controle bloquearem acessos de forma igual a todos os sujeitos quando não fornecidos os elementos mínimos exigidos pela tecnologia, é necessário compreender que o controle de todos não é a prerrogativa desses mecanismos, mas eles são e estão pautados em pressupostos de alargamento de vigilância, nos quais vigia-se o maior número de pessoas possível, na expectativa de controlar propriamente os movimentos - imediatos e futuros - de um número reduzido de sujeitos. Entre as novas faces da redistribuição dos 
poderes de controle, verifica-se que a seleção ou definição dos sujeitos implicados na lógica da (in)segurança internacional e do policiamento da era global (BIGO, 2006, p. 35) se dá através da elaboração de perfis traçados não necessariamente pelo poder punitivo, mas numa roupagem burocrática/administrativa.

O modelo panóptico, pode-se dizer, está mais vivo que nunca, goza de boa saúde e, tal como um cyborg, é dotado hoje de uma musculatura melhorada eletronicamente. Controlar o ambiente hoje traz consigo, como afirma Virilio (1996, p. 56-57; p. 122-123), uma verdadeira "dromopolítica", em que a velocidade da luz passa a ser o paradigma temporal, em que um saber/poder será ainda mais adequadamente complementado com um poder/mover. A política da velocidade atravessa os corpos, encurta distâncias e coloca o tempo comprimido numa instantaneidade. 0 "tele-presente-vivo" de uma "dromologia" nos impõe condicionantes inafastáveis.

A "videoscopia", com seu papel principal de iluminar, oferecer a visão direta de um lugar eletromagneticamente, desempenha um papel de fenômeno de pura transmissão que torna supérfluo aquilo que se ilumina, seja ele um lugar ou um homem (VIRILIO, 1993a, p. 13). Despreza a dimensão física. $\mathrm{O}$ vídeo passa a constituir ativamente um direto em tempo real. 0 declínio do lugar ou dos sujeitos reais a serem apresentados sustenta uma tele-realidade que suplanta a realidade da presença dos objetos, lugares e pessoas. Assistimos, assim, a uma "co-produção" da realidade sensível, na qual as percepções diretas são, repita-se, mediatizadas, senão confundidas, com a representação instantânea do ambiente que projetam, desequilibrando perigosamente o sensível e o inteligível (VIRILIO, 1993b, p. 23).

O tempo real da informação pública, por outro lado, desencadeia a imagem pública como vetor a substituir o próprio espaço público, e escancara a fragilidade da cena política que não dispensa mais a forma-imagem (VIRILIO, 1993b, p. 25). 0 estreitamento das distâncias de uma parte, com a sua realidade estratégica de consequências políticas incalculáveis, equivale à negação do espaço físico: "o valor estratégico do não-lugar da velocidade suplantou definitivamente o do lugar" (VIRILIO, 1996, p. 123). Para que então interessaria o território se ele é dispensável pelo projétil? 
No Banóptico, através do argumento proposto por Bigo, a negação do território consiste no exercício de um novo método de vigilância, no qual o

[...] dispositivo aparece como uma montagem virtual (morphing) de todas as posições dos indivíduos no processo de fluxo. De uma imagem inicial (do imigrante, dos jovens do gueto) a uma imagem final (do terrorista, do traficante), todos os passos de transformação são reconstituídos virtualmente. Neste sentido, o dispositivo flui em vez de examinar corpos. Como o dispositivo panóptico, este dispositivo banóptico de "montagens" produz um conhecimento, bem como declarações sobre ameaças e sobre segurança que reforçam a crença na capacidade de decifrar, antes mesmo do próprio indivíduo, quais serão suas trajetórias e seus itinerários. Este dispositivo depende do controle de movimento mais do que o controle da ação em um território." (BIGO, 2006, p. 44, tradução nossa).

Somos em alguma medida inundados por um tempo de uma exposição "cronoscópica" que se sobrepõe à realidade física. Transparência dos meios ópticos que agora fazem "trans-aparecer", aparecer através deles, portanto, dar a ver as aparências transmitidas instantaneamente a distância, não meramente como faz o ar, a água ou o vidro, mas transmitindo eletronicamente a aparência das coisas (VIRILIO, 1993b, p. 102; VIRILIO, 1993a, p. 86). Uma aparência tornada, sem esforço algum, uma evidência desde sua nova forma-imagem.

Quando o espaço comprime-se ao extremo - por onde quer que se vá não há mais como estendê-lo -, é o controle absoluto que é entrevisto, no polo da inércia total, onde tudo permanece, em seu frenético movimento, controlado. Facilmente se percebe o estático que se encontra no sucedâneo do deslocamento contínuo: invenção da "mobilidade imóvel"? (VIRILIO, 1993a, p. 33). Deslocamentos infinitos não ficam indiferentes ao veículo estático, ao imobilismo ou, noutras palavras, ao alvissareiro triunfo do controle, que parece agora definitivo.

Atmosfera extraordinariamente exposta que, se deixasse algo à sombra de sua velocidade, apenas seria aquilo crispado de onipotência, onipresença e onividência funcionais. É desta forma que o controle do ambiente, exponencialmente elevado pela velocidade da informação - além de ser acompanhado de um fechamento do homem em si, "ego-centrado" corporal e temporalmente -, tende a tornar-se absoluto. 0 
homem, assim, "mediado", onipresentemente pelo controle, encontra aí o seu meio ambiente último (VIRILIO, 1993a, p. 122 e 116).

A interface das telas de controle, outra superfície-limite, ignora aquela dos muros e dá a tônica da transformação. E as instituições sociais de controle, sediadas fisicamente em algum lugar, hoje apenas representam fragmentos da crise maior das próprias dimensões físicas. Outro momento tomou conta, aquele das novas instâncias de controle que realizam a percepção dos objetos (humanos): "no instante do olhar, este olhar que é, a um só tempo, o lugar e o olho" (VIRILIO, 1993b, p. 48).

A rigor, o que a caserna, o hospício e a prisão, para além do problema de exclusão e enclausuramento, foram chamados a responder - e que nos dias de hoje vem alcançando uma visibilidade inédita - diz respeito à tentativa de resolver um problema de circulação (VIRILIO, 1996, p. 23). Instituições que não somente se modificam em seu interior, mas que também se adaptam às novas demandas de controle, como a da dominação globalizada (BIGO, 2006, p. 7), produzem dispositivos que podem ser reconhecidos como novos espaços penitenciários - vide as "zonas de espera (waiting zones) de aeroportos que reproduzem as mesmas condições carcerárias da prisão, mas sem a condenação através do devido processo legal" (BIGO, 2006, p. 7).

Fora de circulação expropriando a vida no abandono daquele que não tem outra identidade que não seja sua falta de identidade, posto ao esquecimento como condição miserável do ser, cuja própria miséria é o que fomenta o esquecimento. Imóvel e mudo, esfinge de pedra, o abandono daquele que se entrega ao poder soberano e à sua sentença, abandonado a uma lei que lhe veda o retorno. É na medida dos rigores sem limites da lei a qual se encontra exposto que se antevê a vida nua do excluído para fora da circulação que compreende a própria concepção de inclusão (NANCY, 1983, p. 6). A retórica antiterrorista ou a ameaça constante de crimes sempre com a previsão de gravidades incalculáveis - ocultam a ordem de manter afastado o estrangeiro pobre e o refugiado (BIGO, 2006, p. 44) o mais distante possível através do controle de mobilidade das populações. É o abandono pela lei soberana do estado permanente de emergência.

Enfrentamento que hoje naturalmente pode bem dispensar os arcabouços institucionais para se intensificar. 0 extermínio do espaço 
com a guerra pelo tempo, em que um estado de urgência é tomado automaticamente como política ou razão de estado, eleva a "violência desta velocidade" como o "lugar da lei". Basta, assim, citarmos as normas obrigatórias de controle destas novas infraestruturas para se constatar uma funesta relação: "quanto mais cresce a rapidez, mais decresce a liberdade" (VIRILIO, 1996, p. 130 e 137).

Não necessariamente estamos proclamando um tipo novo de sociedade, mas evitaremos equívocos se estivermos próximos de perceber neste mesmo sintoma uma característica maior daquilo que se poderia chamar de uma sociedade da sensação, fruto inseparável do estado de inquietude geral, de excitação e de efervescência constantes (TÜRCKE, 2010, p. 9). A mobilização das subjetividades pelo medo (ŽIŽEK, 2008, p. 40), insegurança correlata do controle e das liberdades limitadas, são apenas pequenas representações desta constelação.

Aquilo que, de alguma parte, inflacionado pelo rufar dos tambores audiovisuais, dá as cartas é uma compulsão a emitir que acaba por ser a marca original da globalização microeletrônica. Isto apenas sinaliza desdobramentos tais para, antes de mais nada, suspeitarmos permanentemente dos auspícios da dita integração que a acompanha como discurso. Sempre latente o alerta adorniano sobre os falsos idílios da integração:

[...] genocídio é a integração absoluta que se prepara por toda parte onde os homens são igualados, aprumados, como se costuma dizer na linguagem militar, até que as pessoas literalmente os exterminam, desvios do conceito de sua perfeita nulidade. Auschwitz confirma o filosofema da pura identidade com a morte. (ADORNO, 2009, p. 300).

Jean-Luc Nancy, ao refletir sobre a ontologia do abandono, provoca-nos a pensar o extermínio a partir da "cessação ou suspensão dos discursos, das categorizações, das interpelações e das invocações, cuja copiosidade constitui o ser do ser" (NANCY, 1983, p. 141, tradução nossa), no qual a exclusão alcança toda a sua jurisdição. 0 excluído submete-se à lei em sua totalidade, é banido ao esquecimento, elimina-se qualquer rastro de memória possível, não há recordação, anula-se qualquer hipótese de lugar designado, "garantindo-lhe somente a permissão do olhar lançado para um local que não tenha o que se ver"(NANCY, 1983, p. 
141-142, tradução nossa). Na transnacionalidade, pensar o extermínio através do abandono é refletir sobre as promessas de livre circulação que se elaboram como meio de legitimar a violência da exclusão, é necessariamente questionar quem não é contemplado pelos mitos da liberdade das regras suspensas pela emergência da restrição.

Dizer, a rigor, que os "excluídos" sempre foram integrados às sociedades, sendo alijados apenas de seus benefícios decisivos, é se aproximar daquilo que é o cerne da questão. Mas não o suficiente. Atualmente, arrisca-se a dizer com Türcke, que se perdeu basicamente a ideia de que é necessário antes integrar para haver a posterior exclusão, quer dizer, a integração não é um somente fator secundário, mas propriamente o "fator primário de adaptação forçada [...] [relacionado] com a natureza da moderna socialização capitalista" (TÜRCKE, 2010, p. 61). Somente poderá ser excluído aquele que anteriormente já estava integrado às coerções do grupo como um todo. 0 instante social que se firmou privilegiado e diferenciador desta agregação foi o mercado. Principalmente, com a sua nova função de instância de socialização, em que cada um se obriga também a se colocar à venda. Adiante de um local de simples troca de mercadorias, o seu poder de seleção acaba por ter como precondição este poder de integração.

Decisivo é atinar para a imbricação integração/exclusão. Algumas desagregações, como a do estado de bem-estar social, como a das instituições, que dirá a prisão, são evidentes, entretanto tudo que desmorona são "integrações secundárias", onde a própria base permanece incólume - o poder de integração primário, a força de sucção do mercado. Se a exclusão é degradante, não menos grave poderá ser a dita integração, tão abrangente e óbvia quando pouco percebida.

A ampliação do controle liga-se à gestão do movimento a partir do propósito de antecipar comportamentos futuros. As tecnologias securitárias que se moldam a partir de novas práticas de poder também estabelecidas na vigilância a distância criam "zonas de esperas" transnacionais. Esses espaços são destinados para que sujeitos, que por elementos quaisquer - cor de pele, sotaque ou "atitude suspeita" -, sejam convocados pela voz da lei para retirarem-se do país. É através dos mecanismos de controle a distância que se administram como política de segurança movimentos 
populacionais. As ferramentas de poder se alteram constantemente, mas se destacam pela banalidade de sua atribuição "administrativa" como mecanismos burocráticos comuns: "vistos, controles de companhias aéreas, deportação e readmissão” (BIGO, 2006, p. 20).

Enfim, entram em jogo, às cegas, novos tipos de dispositivos. Dirá vez mais Deleuze (1992, p. 216) “face às formas próximas de um controle incessante em meio aberto, é possível que os confinamentos mais duros nos pareçam pertencer a um passado delicioso e benevolente”. É da crise generalizada dos meios de confinamento, das candentes e sempre urgentes "reformas", que nascem as novas configurações de controle. Pouco importará perguntar o que é pior - devendo-se temer ou esperar -, mas se impõe buscar novas ferramentas e surpreender, a todo momento, estes incipientes agenciamentos coletivos (DELEUZE, 1992, p. 220).

\section{CONCLUSÃO}

Fundamental é, portanto, o argumento de Bigo (2006), que através do conceito de "banóptico" indica como as técnicas de elaboração de perfis são utilizadas para saber quem deve ser objeto de vigilância direta. A vigilância e os controles transnacionais burocráticos trabalham agora a distância para rastrear e controlar até mesmo os movimentos de populações. 0 resultado não é apenas o de pessoas excluídas por um determinado Estado-nação, senão por um conglomerado amorfo de poderes globais. 0 diagrama estratégico consiste em determinar uma minoria como excluída, desde discursos de riscos e inimigos internos, passando pelas instituições como os centros de detenção até as portas de embarque dos aeroportos, cruzando-se com leis e medidas administrativas que singularizam o tratamento de certo grupo. Em resumo, três elementos constituem este poder excepcional: a regra do estado de emergência, a seleção que exclui categorias sociais inteiras por seu comportamento social futuro e a normalização de grupos não excluídos mediante a crença na livre circulação de bens, capitais, informação e pessoas.

Há um certo processo de saturação de uma lógica centrada num dispositivo geral de governamentalidade, tal como foi instalada já no 


\section{século XVIII, isto é firme. Mas tal momento faz parte exatamente da instância preparatória para um novo jogo acerca do custo econômico do exercício das liberdades. Novas práticas podem evidenciar antigos equí- vocos, travestindo-se no apelo ao que se poderia denominar - pedindo emprestada a expressão e introduzindo-se num contexto semelhante - de "dispositivos liberógenos" (FOUCAULT, 2008, p. 93) que, destinados a produzir liberdade, assumem e produzem exatamente o inverso. Para- fraseando Deleuze, que a cegueira das toupeiras não nos deixe menos atentos ao bote da serpente.}

\section{NOTAS}

1 De longa e profunda genealogia, a noção de "biopolítica" é uma categoria de fácil apreensão, porém há uma matriz conceitual com múltiplos sentidos. 0 conceito de "biopoder" pode ser basicamente entendido como: "o conjunto de mecanismos por meio dos quais aquilo que, na espécie humana, constitui seus traços biológicos fundamentais poderá ser parte de uma política, de uma estratégia política, de uma estratégia geral de poder; em outras palavras, como, a partir do século XVIII, a sociedade, as sociedades ocidentais modernas, tomaram em conta o fato biológico fundamental de que o homem constitui uma espécie humana." (FOUCAULT, 2006c, p. 15, tradução nossa). Noutros termos, é a politização da vida que captura o humano, sobremaneira a partir da modernidade, e indica o início de uma ambivalência: a vida tanto como sujeito quanto objeto da política. Ademais, vale conferir CASTRO, 2011, p. 15-37 e, sobretudo, ESPOSITO, 2011, p. 22-72. Na obra de Foucault, contudo, aparece a categoria de "biopolítica" pela primeira vez no ano de 1974 quando proferiu no Brasil uma conferência sobre "o nascimento da medicina social". Disse: "o controle da sociedade sobre os indivíduos não se opera simplesmente pela consciência ou pela ideologia, mas começa no corpo, com o corpo. Foi no biológico, no somático, no corporal que, antes de tudo, investiu a sociedade capitalista. 0 corpo é uma realidade bio-política. A medicina é uma estratégia bio-política." (FOUCAULT, Michel. 1979, p. 80). A abordagem foi objeto de concentração ao longo de três cursos no Collège de France, a saber, "Em defesa da sociedade" (FOUCAUlT, 2006a), "Segurança, População e Território" (referido acima) e "Nascimento da Biopolítica" (FOUCAULT, 2008). Mas foi no ano de 1976, com a publicação do primeiro volume da "História da Sexualidade: a vontade de poder" (FOUCAULT, s/d.), que o autor francês começa a minuciosamente detalhar sua empreitada, mesmo ano do primeiro seminário referido, no qual apresenta as duas formas de poder: o poder disciplinar e o biopoder. Assim, já estamos diante do estudo daquela forma de poder que se exerce sobre a população, a vida e os vivos e que penetra todas as esferas da existência e as mobiliza inteiramente (cf. PELBART, 2011, pp. 55-60).

2 Quando Foucault utiliza esta expressão "governamentalidade", ele alude a três aspectos: "entendo [primeiro] o conjunto constituído pelas instituições, os procedimentos, análises e reflexões, os cálculos e as táticas que permitem exercer essa forma bem específica, ainda que muito complexa, de poder que tem por alvo principal a população, por forma maior de saber a economia política e por instrumento técnico essencial os dispositivos de segurança. Segundo, por 'governamentalidade' entendo a tendência, a linha de força que, em todo o Ocidente não deixou de conduzir e desde faz muito, trazia a preeminência do tipo de poder que podemos chamar 'governo' sobre todos os demais: soberania, disciplina, e que induziu, por um lado, o desenvolvimento de toda uma série de aparatos específicos de governo, [e por outro] o desenvolvimento de toda uma série de saberes. Por último, creio que havia que entender a 'governamentalidade' como o processo, ou melhor, o resultado do processo em virtude do qual o Estado de Justiça da Idade Média, con- 
vertido em Estado Administrativo durante os séculos XV e XVI, se 'governamentalizou' pouco a pouco" (FOUCAULT, 2006c, p. 136). Além disso, para evitar maiores riscos de uma certa diluição conceitual e uma perda de força analítica que a banalização do uso do termo pode levar, cf. a rigorosa análise de DEAN, 1999.

3 Inspiram esta parte os impasses traçados, fundamentalmente, nas suas intervenções reunidas sob o título Conversações, em especial, o capítulo V (Política), que reúne uma entrevista com Toni Negri, “Controle e Devir", e outro texto publicado no L'Autre Journal, intitulado "'Post-scriptum" sobre as sociedades de controle" (DELEUZE, 1992, p. 209 ss).

4 Escritor e pintor, ícone da cultura beatnik, quem cunhou propriamente a expressão "sociedade de controle" (dentre outros termos, também o "heavy-metal") e destacado inclusive na célebre capa do álbum "Sgt. Pepeers" dos Beatles. Cf. BURROUGHS, 2009.

5 Antes, em escala mundial, sobre as bases de dados pessoais como forma de radicalização das formas de controle, ver DELMAS-MARTY, 2010, p. 68-76.

\section{REFERÊNCIAS}

ADORNO, Theodor W. Dialética negativa. Tradução Marco Antonio Casanova; revisão técnica Eduardo Soares Neves Silva. Rio de Janeiro: Jorge Zahar Ed., 2009.

BIG0, Didier. Globalized (in)security: the Field and the banopticon. In: SAKAI, Naoki; SOLOMON, Jon (comps). Traces 4: Translation - Biopolitics, Colonial Difference. Hong Kong: Hong Kong University Press, 2006.

BURROUGHS, William. Naked lunch. The Fiftieth Anniversary Edition. New York: Grove Press, 2009.

DELEUZE, Gilles. Conversações (1972-1990). Tradução de Peter Pál Pelbart. São Paulo: Ed. 34, 1992.

Foucault. Tradução de Cláudia Sant'Anna Martins (et. al.). São Paulo: Brasiliense, 2006.

DELMAS-MARTY, Mireille. Libertés et sûrete dans un monde dangereux. Paris: Éditions du Seuil, 2010.

FOUCAULT, Michel. 0 nascimento da biopolítica. Curso dado no Collège de France (1978-1979). Edição estabelecida por Michel Senellart sob a direção de François Ewald e Alessandro Fontana. Tradução Eduardo Brandão. São Paulo: Martins Fontes, 2008.

É preciso defender a sociedade. Curso no Collège de France (1975-1976). Tradução de Carlos Correia Monteiro de Oliveira. Lisboa: Livros do Brasil, 2006a. 
. Omnes et Singulatim [para uma crítica da razão política]. Tradução de Selvino J. Assmann. Desterro: Nephelibata, 2006b.

. Seguridad, Territorio, Población. Curso en el Collège de France (19771978). Edicción establecida por Michel Senellart, bajo la dirección de François Ewald y Alessandro Fontana. Traducido por Horacio Pons. Buenos Aires: Fondo de Cultura Económica, 2006c.

Os anormais. Curso no Collège de France (1974-1975). Edição estabelecida sob a direção de François Ewald e Alessandro Fontana, por Valério Marchetti e Antonella Salomoni. Tradução Eduardo Brandão. São Paulo: Martins Fontes, 2001.

. Vigiar e Punir: nascimento da prisão. 19. ed. Tradução de Raquel Ramalhete. Petrópolis: Vozes, 1987.

. Microfísica do poder. Tradução de Roberto Machado. Rio de Janeiro: Graal, 1979.

História da sexualidade 1: a vontade de saber. 10. ed. São Paulo: Graal, $[\mathrm{s} / \mathrm{d}]$.

GOFFMAN, Erving. Manicômios, prisões e conventos. Tradução de Dante Moreira Leite. São Paulo: Perspectiva, 1999.

MARTINS, Rui Cunha. El Método de la Frontera: radiografía histórica de un dispositivo contemporáneo (matrizes ibéricas y americanas). Traducción de Manuel del Pino. Salamanca: Universidad de Salamanca, 2007.

NANCY, Jean-Luc. L'Imperatif catégorique. Paris: Flammarion, 1983.

PASSETTI, Edson. Poder e Anarquia: apontamentos libertários para o atual conservadorismo moderado. Verve, Perdizes, n. 12, p. 11-43, 2007.

TÜRCKE, Christoph. Sociedade excitada: filosofia da sensação. Tradução de Antonio A. S. Zuin [et al.]. Campinas: UNICAMP, 2010.

VIRILIO, Paul. A inércia polar. Lisboa: Don Quixote, 1993a. 
O espaço crítico e as perspectivas do tempo real. Tradução de Paulo Roberto Pires. Rio de Janeiro: Ed. 34, 1993b.

. Velocidade e Política. Tradução de Celso M. Paciornik. São Paulo: Estação Liberdade, 1996.

WACQUANT, Loïc. Os condenados da cidade: estudo sobre a marginalidade avançada. Tradução de João Roberto Martins Filho et al. Rio de Janeiro: Revan/ FASE, 2001.

WARAT, Luis Alberto. A Rua Grita Dionísio! Direitos Humanos da Alteridade, Surrealismo e Cartografia. Tradução e organização de Vivian Alves de Assis, Júlio Cesar Marcellino Jr. e Alexandre Morais da Rosa. Rio de Janeiro: Lumen Juris, 2010.

ŽIŽEK, Slavoj. Órganos sin Cuerpo: sobre Deleuze y consecuencias. Traducción de Antonio Gimeno Cuspinera. Valencia: Pre-Textos: 2006.

Violence: six sideways reflections. New York: Picador, 2008.

Recebido em: 6-10-2017

Aprovado em: 24-1-2018

\section{Fernanda Martins}

Doutoranda em Ciências Criminais PUC/RS, bolsista CAPES; mestre em Direito pela Universidade Federal de Santa Catarina (UFSC), na área de Teoria, Filosofia e História do Direito. Professora de Criminologia, Direito Penal e Processo Penal na Universidade do Vale do Itajaí (UNIVALI); integrante do Projeto de Pesquisa Bases para uma Criminologia do controle penal no Brasil: em busca da brasilidade criminológica - CNPq e do Projeto de Extensão Universidade Sem Muros - UFSC e do projeto de pesquisa Criminologia, Cultura Punitiva e Crítica Filosófica - Cnpq - PUC/RS. E-mail: fernanda.ma@gmail.com

Pontifícia Universidade Católica do Rio Grande do Sul, Faculdade de Direito (FADIR).

Av. Ipiranga 6681, Partenon. 90619900 - Porto Alegre, RS - Brasil. 


\section{Augusto Jobim do Amaral}

Doutor em Altos Estudos Contemporâneos (Ciência Política, História das Ideias e Estudos Internacionais Comparativos) pela Universidade de Coimbra (Portugal); doutor, mestre e especialista em Ciências Criminais pela Pontifícia Universidade Católica do Rio Grande do Sul (PUCRS); professor do Programa de Pós-Graduação em Ciências Criminais (PPGCCrim/mestrado e doutorado) da Pontifícia Universidade Católica do Rio Grande do Sul (PUCRS). E-mail: guto_jobim@hotmail.com

Pontifícia Universidade Católica do Rio Grande do Sul, Faculdade de Direito (FADIR).

Av. Ipiranga 6681, Partenon. 90619900 - Porto Alegre, RS - Brasil. 
